\title{
Learning Needs Determination for Industry 4.0 Maturity Development in Automotive Organisations in Slovakia
}

DOI: 10.12776/QIP.V24I3.1521

\author{
Andrea Sütőová, L’ubomír Šooš, Ferdinand Kóča \\ Received: 2020-10-12 Accepted: 2020-11-13 Published: 2020-11-30
}

\begin{abstract}
Purpose: This paper aims to present the results of the study focused on the assessment of Industry 4.0 (I4.0) maturity level and adoption level of Quality 4.0 (Q4.0) intelligent technologies in organisations operating in the automotive industry in Slovakia (OEMs, Tier 1 and Tier 2 suppliers). The results serves as inputs for identification of learning and development needs.
\end{abstract}

Methodology/Approach: The background of the study was a literature review and quantitative research. The I4.0 maturity model published by PwC (2016) was used in the study, while dimension elements were adjusted to the specifics of the automotive industry.

Findings: Tier 1 and Tier 2 automotive suppliers are in the early stages of I4.0 maturity and adoption of Q4.0 intelligent technologies. OEMs achieve the level of horizontal collaborators in most of the dimensions. Q4.0 intelligent technologies are mostly adopted at an average level. Further development of OEMs to achieve the level of digital champions requires new disruptive business models and a fully integrated partner ecosystem.

Research Limitation/Implication: The research is limited by the sample size and target levels of particular dimensions, related elements and Q4.0 intelligent technologies, which were not examined.

Originality/Value of paper: The results bring more in-depth insight into the current state of I4.0 maturity and Q4.0 technology adoption level of the automotive organisations in Slovakia. There is no evidence of the study examining holistically the I4.0 maturity and Q4.0 technologies in the automotive.

Category: Research paper

Keywords: Industry 4.0; Quality 4.0 intelligent technologies; self-assessment; automotive industry; learning and development 


\section{INTRODUCTION}

Nowadays, the automotive industry is facing incredible challenges like changing customer needs, mass customization, pressures to accelerate innovation and increase efficiency and issues of sustainability shifting production to electric vehicles. The increasing demand for the customized product from the customer end is a significant theme forcing transformation in the automotive industry. Traditional car production involving hundreds of identical vehicles lined up in a row is no longer possible. The current megatrends on the automotive market require the implementation of new technologies and business models.

A century later, after Henry Ford introduced mass production, the concept of Industry 4.0 (I4.0) is penetrating in the automotive industry as well as other sectors. Getting on the 4th Industrial Revolution train is not an option, but rather an obligation for organisations to be competitive. The new industrial paradigm brings together the digital and physical worlds through the Cyber-Physical Systems (CPS) enhanced by the Internet of Things (IoT), and it is expected that this novel has consequences on industry, markets, and economy, improving production processes and increasing productivity (Pereira and Romero, 2017). I4.0 is also getting to the field of quality management. Quality 4.0 (Q4.0) leverages intelligent technologies and can help to improve the quality of products and services and differentiate a brand within its market. Several studies have presented the positive impact of I4.0 on firm's performance and competitiveness, e.g. (Llopis-Albert, Rubio and Valero, 2021; Buchi, Cugno and Castagnoli, 2020; Sanders, Elangeswaran and Wulfsberg, 2016). In comparison to other sectors, the automotive industry belongs among the front runners in terms of digital maturity (Wellner, Manolian and Laaper, 2018; Geissbauer, Veds $\varnothing$ and Schrauf, 2016). Some Original Equipment Manufacturers (OEMs) and leading players in a supply chain are already experiencing the benefits resulting from I4.0. The Slovak automotive industry does not stand away from the digital transformation, and the future success of the sector is a key for the whole economy of Slovakia. For OEMs and especially automotive suppliers the adoption of I4.0 is challenging. To implement the route appropriately, a tool such as Maturity Model $(\mathrm{MM})$ can be useful and help to guide on the way to I4.0 excellence. Holistic assessment of I4.0 maturity and identification of problematic fields and elements for defining future learning and development needs can help to achieve improvements and ensure competitiveness in the future. Several MMs have been developed, which will be discussed within the theoretical overview, however, there is no evidence of the study focusing on I4.0 maturity assessment in the automotive industry or adjustment of dimensional elements of existing MMs to the specifics of the automotive industry. The paper contributes to fill the knowledge gap and contributes to the possibility of identification of learning and development needs to fulfil I4.0 strategy and related Q4.0 intelligent technologies adoption in OEMs, Tier 1 and Tier 2 suppliers operating in Slovakia. 
The structure of the paper is as follows. The theoretical overview deals with the I4.0 impact on the automotive industry and quality assurance, it also presents the main information regarding the automotive industry in Slovakia and summarizes I4.0 MMs published by academics and consulting organisations. The methodology section provides an overview of the selected and adjusted MM used in the study and presents the flowchart describing the steps carried out within the study by the authors. The results of I4.0 maturity assessment and adoption level of Q4.0 intelligent technologies are presented individually for OEMs, Tier 1, and Tier 2 in the following section.

\section{THEORETICAL BACKGROUND}

\subsection{Industry 4.0 and Quality 4.0 Intelligent Technologies in the Automotive Industry}

The automotive industry is undergoing a massive transformation and much of it is being driven by I4.0. I4.0 is a name for the current trend of automation and data exchange in the manufacturing industry. Within the modular structured Smart Factories of I4.0, Cyber-Physical Systems (CPS) monitor physical processes, create a virtual copy of the physical world and make decentralized decisions. Over the Internet of Things (IoT), CPS communicate and cooperate with each other and humans in real-time (Boyes et al., 2018). I4.0 brings a new level of organisation and control of the entire value-chain, it is geared towards increasingly individualized customer requirements. I4.0 aim is to work with a higher level of automation, flexibility and efficiency (Alcácer and CruzMachado, 2019).

I4.0 affects the automotive value chain, including design, production, distribution, and services. The interconnection of the value creation process takes place across corporate functions, companies, and entire value creation chains, where IoT provides connectivity from end-to-end (Markulik, Sinay and Pačaiová, 2019). Data generated in each area are also available to other areas in real-time and provides information transparency. I4.0 organizes suppliers, manufacturers, and customers in a virtual, vertically and horizontally integrated value chain. Therefore, automotive suppliers need to implement I4.0 strategy and appropriate technologies to avoid losing their position and fully integrate into the customer's network. Improved connectivity between each part of the supply chain allows stakeholders to adjust to customer demand more quickly and ultimately reduce time to market.

Big Data, automation, interconnections along the value chain and digital customer interfaces create a foundation for new business models (Rachinger et al., 2019). Advanced OEMs are switching to customer-centric business models with more services. In the past, OEMs saw themselves primarily as providers of hardware. Now, they are beginning to evolve into providers of digital services. 
The shifting focus from products to services leads to new value propositions to consumers, requires new value creation activities, new partnerships, and asks for new revenue models (Athanasopoulou et al., 2019). Innovative, interconnected business models are necessary to deal with new actors in the ecosystem. Companies must develop ecosystems of partners, establish multi-speed capabilities, and completely rewire their product development processes. Thus, vehicles are no longer regarded as isolated tangible goods, but as objects that integrate different stakeholders, devices, functions, and data into coherent systems of value co-creation (Grieger and Ludwig, 2019). Regarding the connectivity, security should be incorporated as a part of any design principle parallel to business strategy. A cyber-secure architecture using IT security needs as a design standard and not as an additional layer that increases complexity enables greater multichannel integration, supporting modularity and protected application programming interfaces (APIs) to permit integration among ecosystem partners.

Increasing vehicles complexity (above all increasing of electronics and software elements) and variety, complex value chains and shortened time-to-market bring new challenges for quality assurance in the automotive industry. Q4.0 leverages the technologies of I4.0, which help to solve quality challenges and provide novel solutions driving organisations toward operational excellence. Quality improvement at industrial transformation is a critical differentiator for businesses. Q4.0 technologies enable real-time data collection, remote monitoring and advanced visualization, big data analysis, predictive quality management, remote diagnosis and maintenance, advanced supply chain management as well as deep integration of quality management methods and processes, such as quality risk analysis and validation, and innovations in production (Krubasik et al., 2017). Q4.0 doesn't replace traditional quality methods, but rather builds and improves upon them (Dan, 2017). According to (Radziwill, 2018) the system of Q4.0 tools is created by Statistics and Data Science; Enabling Technologies (Sensing technologies, Cloud Computing, Extended Reality, IoT, 5 G networks, Internet Protocol Version 6, etc.); Big Data, Blockchain; Deep Learning; Machine Learning and Artificial Intelligence.

Even though Q4.0 is fuelled by technology, success requires a multifaceted approach that addresses the full range of strategic, cultural and already mentioned technological issues. Most studies discuss technical aspects of I4.0 and only a few of them pay attention to organisational culture, which largely influences the success of the implementation of this concept. Appropriate managerial approaches play a vital role in the cultural changes (Mohelska and Sokolova, 2018). Management should top-down initiate cultural changes and serve as a role model, leading by example and providing an unambiguous vision. I4.0 adequate cultural characteristics are high level of willingness to learn, openness to new things, promotion of creativity and idea generation, entrepreneurial mind-set and democratic leadership. Communication is to be opened up so that employees can 
freely communicate and discuss across both hierarchical levels and organisational borders (Veile et al., 2019).

\subsection{Industry 4.0 and Automotive Industry in Slovakia}

Many studies confirm differences in I4.0 readiness and adoption on a country level in the European Union (EU) and world. According to (WEF, 2018) only 25 countries are poised to take advantage of I4.0. The top 10 rated leaders are Switzerland, USA, Germany, Singapore, the United Kingdom, Japan, Sweden, South Korea, Ireland, and Finland. Slovakia is among the so-called "Legacy" group of countries, which need to invest in technology and innovation capacity. The I4.0 readiness index, classifying the countries of the EU on the basis of their effort and progress into 4 groups (frontrunners, potentials, traditionalists, hesitators) showed that countries like Germany, Sweden, Ireland, Finland or Austria belong to frontrunners. Slovakia is in the group of a traditionalist, which means that it has launched few initiatives to take its manufacturing industry into a Digital era so far, but it is behind the leader countries (Berger, 2014). According to Digital Economy and Social Index, especially to the dimension reflecting the Integration of Digital Technology, Slovakia belongs to the group of lower-performing countries among the EU Member States (European Commision, 2019). The studies show that European leading countries are Finland, Sweden, Ireland, United Kingdom, Germany and Slovakia is lagging behind the leaders in I4.0.

The automotive value chain is highly integrated across different EU Member States (Tkáč, Verner and Tkáč, 2019). Therefore, there is a need to increase the level of smart manufacturing in the countries that stay currently behind those who are leading (Konrad and Stagl, 2018). It requires actions on the level of the country as well as organisations to ensure the future competitiveness of the automotive industry. EU supports digital transformation through its industrial policy and through research and infrastructure funding. Member States are also sponsoring national initiatives such as I4.0 in Germany, Alliance pour l'Industrie du Futur in France, High-Value Manufacturing Catapult and Digital Catapult in the United Kingdom, Produktion 2030 in Sweden, etc. Slovakia has supported the concept of Slovakia: Smart Industry from 2016 to foster I4.0 thinking and strengthen the Slovak economy. The Government of the Slovak Republic has recently approved the framework document - Strategy of Digital Transformation 2030. The purpose of the strategy is to increase the involvement of Slovakia into the European Digital Single Market and make Slovakia become a modern country with an innovative and ecological industry by 2030 benefiting from the knowledge-based digital and data economy. The strategy gives priority to current innovative technologies like Artificial Intelligence, IoT, 5G Technology, Big data analysis, BlockChain, and High-Performance Computing, which will become the new engine of economic growth. 
Automotive sector is one of the main pillars of Slovak economy, accounting for $13 \%$ of its gross domestic product and 35\% of its exports (OECD, 2019). Slovakia belongs to the 20 biggest world's car producer and it is the 7 th in the list of the top vehicle producing countries of the EU (ACEA, 2018). Taking into consideration the number of inhabitants, Slovakia is the global leader in car production per pepita. Slovakia has a long term tradition in labour and production quality (Zgodavová, Hudec and Palfy, 2017) and so-called Industry 3.0 was sufficiently developed. After all, the strategic goal of the $1980 \mathrm{~s}$ in Czechoslovakia was to have 3,000 robots and manipulators until the year 2000. This goal was never achieved because of the state-controlled market economy, and there was a downturn in the 1990s, but people were prepared for automation (Slimák and Zgodavová, 2011; Zgodavová, 2002). Over the last 20 years, large foreign direct investments have developed the automotive industry in Slovakia. There are currently 4 OEMs automobile production plants in Slovakia: Volkswagen Slovakia, Kia Motors Slovakia, PSA Peugeot Citroën Slovakia and Jaguar Land Rover. Not only the mentioned automotive producers but also a well-developed supplier network makes the core of the Slovak automotive industry. More than 300 suppliers are operating in Slovakia, and some of Tier 12 suppliers also export their products to plants located around Europe and to other overseas locations (SARIO, 2018).

Entry into the era of I4.0 and the development of autonomous, shared and connected cars are challenges for the automotive industry in Slovakia. Economic history teaches that significant technological changes can strongly alter the functioning and structure of a certain sector (OECD, 2019). As it was mentioned above, Slovakia has already launched some initiatives to support technological development and digitization of the industry. Actions have to be taken also on the level of organisations. OEMs and especially supplier organisation along the value chain have to be aware that increasing digitalization has a significant impact on their future competitiveness (Nagyová et al., 2019). It means that the topic is not only for large but also small and medium-sized organisation down the supply chain (Konrad and Stagl, 2018).

There are many organisations, where only some of the I4.0 elements are present and selected Q4.0 intelligent technologies are implemented, but holistic approach to I4.0 is missing. Some organisations have difficulties to link the I4.0 concept with their business strategy. They also experience problems in determining their state of development with regard to I4.0 and therefore fail to identify a concrete field of actions, programs and projects (Schumacher, Erol and Sihn, 2016). The appropriate model enabling complex assessment of I4.0 maturity helps to identify the organisations current state of development, identify and prioritize learning and development needs and take relevant actions. 


\subsection{Existing Industry 4.0 Maturity Models}

In general, the term "maturity" refers to a "state of being complete, perfect, or ready" and implies some progress in the development of a system. The concept of maturity incorporates the notion of gradual evolution through intermediate stages. The concept of maturity is not new in the industrial engineering and management field. Crosby was among the first to propose, in 1979 the "Quality Management Maturity Grid" model with fives levels of maturity (Facchini et al., 2020). Except the field of Quality Management, the maturity concept has spread into other disciplines. MMs are generally used as tools to conceptualize and measure the maturity of an organisation or a process regarding some specific target state (Schumacher, Erol and Sihn, 2016). MMs are adequate tools for (1) defining and documenting the status quo, (2) developing a strategy of excellence and providing guidance on that development path, and (3) comparing capabilities between business units and organisations (Felch, Asdecker and Sucky, 2019; Bibby and Dehe 2018). MMs can contribute to organisation transformation and renewed competencies in organisation by initiating a change process. In the context of the I4.0 concept, several maturity/readiness models have been developed to identify I4.0 state of development from different perspectives, as it is shown in Table 1.

Table 1 - Existing Maturity Models

\begin{tabular}{|l|l|l|}
\hline Model name & $\begin{array}{l}\text { Consulting } \\
\text { organisation/Author }\end{array}$ & Model focus and assessment approach \\
\hline $\begin{array}{l}\text { Connected } \\
\text { Enterprise Maturity } \\
\text { Model }\end{array}$ & $\begin{array}{l}\text { Rockwell Automation } \\
\text { (2014) }\end{array}$ & $\begin{array}{l}\text { Technology-focused assessment in four } \\
\text { dimensions; 5 stages approach to I4.0 } \\
\text { implementation. }\end{array}$ \\
\hline $\begin{array}{l}\text { IMPULSE- } \\
\text { 4.0 Readiness }\end{array}$ & Lichtblau et al. (2015) & $\begin{array}{l}\text { Focus is on the definition of barriers for } \\
\text { progressing to the next stage and creation of an } \\
\text { action plan to overcome them; based on six } \\
\text { dimensions and 6 maturity levels. }\end{array}$ \\
\hline I4.0 Maturity Model & $\begin{array}{l}\text { Schumacher, Erol and } \\
\text { Sihn (2016) }\end{array}$ & $\begin{array}{l}\text { Focus on strategic decisions and definition of } \\
\text { specific projects and programs on the base of } \\
\text { nine dimensions assessment; 5 maturity levels. }\end{array}$ \\
\hline $\begin{array}{l}\text { I4.0 Maturity Model } \\
\text { I4.0 Digital } \\
\text { Operations Self- } \\
\text { Assessment }\end{array}$ & Pakertilly (2019) & $\begin{array}{l}\text { Consulting tool; Focus on I4.0 maturity } \\
\text { assessment of manufacturing organisation using } \\
\text { nine dimensions and five maturity stages. }\end{array}$ \\
\hline $\begin{array}{l}\text { Maturity Model for } \\
\text { Data-Driven } \\
\text { Manufacturing }\end{array}$ & Weber et al. (2017) & $\begin{array}{l}\text { Application as consulting tool; Focus on } \\
\text { benchmarking and identification of needs for } \\
\text { action; Assessment of six I4.0 dimensions; four } \\
\text { maturity levels. }\end{array}$ \\
$\begin{array}{l}\text { Focus on IT architecture of manufacturing } \\
\text { organisation, assessment of IT with regard to the } \\
\text { requirements of vertical and horizontal system } \\
\text { integration; Only one dimension; five maturity } \\
\text { levels. }\end{array}$ \\
\hline
\end{tabular}




\begin{tabular}{|l|l|l|}
\hline Model name & $\begin{array}{l}\text { Consulting } \\
\text { organisation/Author }\end{array}$ & Model focus and assessment approach \\
\hline $\begin{array}{l}\text { Logistic 4.0 } \\
\text { Maturity Model }\end{array}$ & Facchini et al. (2020) & $\begin{array}{l}\text { Focus on I4.0 technologies in logistic processes; } \\
\text { Assessment of seven dimensions and defining a } \\
\text { roadmap for improvement in five maturity levels. }\end{array}$ \\
\hline $\begin{array}{l}\text { Digital Maturity } \\
\text { Model }\end{array}$ & Capgemini (2018) & $\begin{array}{l}\text { Consulting tool; Focus on holistic Industry 4.0 } \\
\text { readiness; Assessment of 4 main dimensions; } \\
\text { four maturity stages. }\end{array}$ \\
\hline $\begin{array}{l}\text { I4.0 Maturity Model } \\
\text { for delivery in } \\
\text { supply chain }\end{array}$ & $\begin{array}{l}\text { Asdecker and Felch } \\
(2018)\end{array}$ & $\begin{array}{l}\text { Focus on the delivery process in the supply } \\
\text { chain; Assessment of three dimensions and } \\
\text { developing a path in five stages to achieve } \\
\text { delivery excellence. }\end{array}$ \\
\hline
\end{tabular}

On the basis of existing literature sources, it is possible to classify I4.0 MMs into two main categories: holistic and specific. The holistic models aim to assess and utilize elements of I4.0 from all perspectives and hence derive encompassing success factors. The specific MMs focus on the specific areas of I4.0 application or a limited number of aspects related to I4.0 such as logistics (Facchini et al., 2020), supply chain (Asdecker and Felch, 2018), information technologies (Weber et al., 2017). There aren't any modifications of generic I4.0 MMs that take into account the specifics of certain industry sectors in the literature not even specific approaches focusing on the field of Q4.0.

The research presented in this paper is built on the base of so-called holistic I4.0 MMs published by $\mathrm{PwC}$ (2016), while the items in the questionnaire related to individual I4.0 dimensions were adjusted to the specifics of the automotive industry and items related to the field of Q4.0 intelligent technologies were added. Our model systematically assesses the OEMs'; Tier 1 (T1); and Tier 2 (T2) suppliers state-of-development concerning the I4.0 strategy and Q4.0 intelligent technologies adoption. MM serves both a scientific and a practical purpose. The scientific purpose aims at learning and development model for organisations operating in the automotive industry in Slovakia. The research aims to contribute to the possibility of identification of learning and development needs to fulfil I4.0 strategy and related intelligent technologies Q4.0.

\section{RESEARCH METHODOLOGY}

Concerning I4.0, we understand the maturity of the automotive industry as an "industry being driven by digitization and integration of vertical and horizontal value chains, digitization of product and service offerings and the development of new digital business models and customer access platforms" (PwC, 2016). As the framework methodology (Becker, Knackstedt and Pöppelbuß, 2009) step-by-step process was used for the development of the MM which has a theoretical foundation in the design science approach (Hevner, March and Park, 2004) and offers a rigorous methodology. The systematic literature research and review, 
expert interviews, conceptual modelling, and validations as well as testing of the model in automotive organisations were conducted. The Seven-Step I4.0 and Q4.0 Learning and Development Model was designed by the authors, which involves steps carried out within the study by the authors. The designed model is shown in Figure 1. The following of the stages presented in the model enables to measure, identify and graphically present the I4.0 and Q4.0 intelligent technologies state of development at OEMs, Tier 1 and Tier 2 suppliers and identify and discuss main learning and development needs based on the results of the study.

(1) Measurement of I4.0 maturity dimensions and Q4.0 items at OEMs, T1 and $\mathrm{T} 2$ suppliers

(2) Calculation of maturity levels of six I4.0 dimensions and eleven items of Q4.0 intelligent technologies

(3) Representation and visualization of the maturity via radar charts

(4) Comparison of the levels of I4.0 maturity and Q4.0 intelligent technologies adoption among the three segments of respondents

(5) Benchmarking against the best in segment

(6) Indentification of needs for lerning and development

(7) Learning and development in I4.0 and Q 4.0

Figure 1 - Seven-Step I4.0 and Q4.0 Learning and Development Model

Quantitative research was conducted using the structure of (PwC, 2016) questionnaire with adjusted questions to the specifics of the automotive industry. Six dimensions according to (PwC, 2016) were assessed to identify I4.0 maturity level:

- Dimension 1 (D1): Business Model, Product and Service Portfolio business model, product and service digitalization (6 items);

- Dimension 2 (D2): Market and Customer Access - channels used for customer interactions (6 items);

- Dimension 3 (D3): Value Chains and Processes - internal manufacturing integration, supply chain management (5 items); 
- Dimension 4 (D4): IT Infrastructure - technical capabilities and IT support of processes and services (6 items);

- Dimension 5 (D5): Compliance, Legal, Risk, Security - technical implementation of compliance assurance, risk focusing, cyber trust ensuring (6 items);

- Dimension 6 (D6): Organisation and Culture - collaboration and culture supporting I4.0 (4 items).

The evolution path of each dimension undergoes five maturity levels, where Level 1 describes a complete lack of attributes supporting the strategy of I4.0, Level 2 represents a Digital Novice, Level 3 is a Vertical Integrator, Level 4 is a Horizontal Collaborator and Level 5 represents a Digital Champion, what means the state-of-the-art of required attributes. The example of a question to assess one of the items related to $D 1$ is shown in Table 2 .

Table 2 - Example of the Guestion Related to Dimension 1

\begin{tabular}{|c|c|c|c|c|c|}
\hline Question & 1 & 2 & 3 & 4 & 5 \\
\hline $\begin{array}{l}\text { To which degree are the life cycle phases of } \\
\text { your products digitized (digitization and } \\
\text { integration of design, planning, engineering, } \\
\text { production, services \& recycling)? }\end{array}$ & $\square$ & $\square$ & $\square$ & $\square$ & $\square$ \\
\hline \multicolumn{6}{|c|}{$\begin{array}{l}1 \text { - Low level of digitization \& integration: Isolated IT enablement of different steps in } \\
\text { product life cycle (e.g. no integration of engineering and production) } \\
5 \text { - Complete digitization \& integration: All phases in the product life cycle are completely } \\
\text { digitized (e.g. producibility can directly be tested during product development via virtual } \\
\text { prototyping) }\end{array}$} \\
\hline
\end{tabular}

The second part of the questionnaire examining the intensity of Q4.0 intelligent technologies adoption included 11 items based on the study of (Radziwill, 2018): Sensing Technologies including QR codes, sensors, actuators; IoT; Big Data (BD); Cloud Computing (CC); Machine Learning (ML); Deep Learning (DL); Artificial Intelligence (AI); Data Science (DS); Blockchain (BCh); Additive Manufacturing (AM); Extended Reality (ER) including augmented reality, virtual reality, mixed reality. Five-point Likert-scale was used to assess the level of adoption of intelligent technologies in the field of quality management. The example of the question is shown in Table 3.

Table 3 - Example of the Question Related to Q4.0 Technology Adoption

\begin{tabular}{|l|llllll|}
\hline Question & 1 & 2 & 3 & 4 & 5 \\
\hline $\begin{array}{l}\text { To what extent do you use sensing technologies } \\
\text { such as "QR codes, sensors, and actuators" within } \\
\text { quality management? }\end{array}$ & $\square$ & $\square$ & $\square$ & $\square$ & $\square$ \\
\hline $\begin{array}{l}1-\text { Not at all } \\
5-\text { To a very great extent }\end{array}$ & & & & & \\
\hline
\end{tabular}


The online questionnaire was sent to three types of organisations operating in the automotive industry in Slovakia - OEMs, Tier 1 suppliers, and Tier 2 suppliers. The respondents represented by quality managers, and production managers of organisations were contacted personally or by phone to give them more detailed information and ensure feedback relevance. It was very important to explain to them the concept of I4.0 a related Q4.0 meaning because the questionnaire can only be adequately answered if all respondents have a basic understanding of the theme. This is how we ensured the questionnaire's representability and the MM's accuracy. The organisations involved in the study were selected from the database. Totally 308 organisations are operating in the automotive industry in Slovakia. Organisations with financial data were selected for the research. E-mail based distribution of questionnaires to 107 respondents resulted in 73 responses. The OEM segment was represented by all 4 car manufacturers $(6 \%)$ and the remaining responses were accounted for 51\% of Tier 1 suppliers and $43 \%$ of Tier 2 suppliers. The data were graphically represented by radar charts and compared.

\section{RESULTS AND DISCUSSION}

Figure 2 shows the average values of individual dimensions for the three segments of respondents, where OEMs achieve the highest values in all dimensions. The OEMs achieved the level of Horizontal Collaborator except for the lowest-rated $D 3$ and $D 6$, where the average values are below 4.0. The OEMs need to focus on horizontal integration of processes and data flows with customers and suppliers and strengthening of collaboration across company boundaries and support knowledge sharing. Further development to achieve the level of Digital Champions requires new disruptive business models with innovative product and service portfolio, a fully integrated partner ecosystem with self-optimized and virtualized processes, and related secure data exchange.

Most of the dimensions at Tier 1 suppliers achieve the level of Vertical Integrator with vertical digitization and integration of processes and data flows within company and homogenous IT architecture in-house. The $D 2$ and $D 6$ were rated on the level of Digital Novice. Attention should be focused on an individualized customer approach, building customer platforms and channels and developing of a cross-functional collaborative culture. Half of the dimensions at Tier 2 suppliers achieved the level of Vertical Integrator (D1,D3 and D5), however, the values of the D2,D4 and D6 are on the level of Digital Novice. The weaknesses are fragmented IT architecture in-house, isolated applications, low customer focus and culture, which doesn't support enough cross-functional collaboration. Average dimension levels achieve the lowest values at Tier 2 suppliers. Tier 1 suppliers rated the dimensions slightly higher than Tier 2 suppliers. To remain in supply chains and be competitive, suppliers must focus on the critical areas, which don't even reach the level of Vertical Integrator. To fully integrate into customer's network suppliers need to move their I4.0 maturity to the next level of Horizontal Collaborator, what requires horizontal process integration and data 
flows with customers and external partners, common IT architectures and collaborative culture supporting I4.0 concept. Figure 2 shows the average values of individual dimensions for the three segments of respondents, while OEMs achieves the highest values in all dimensions.

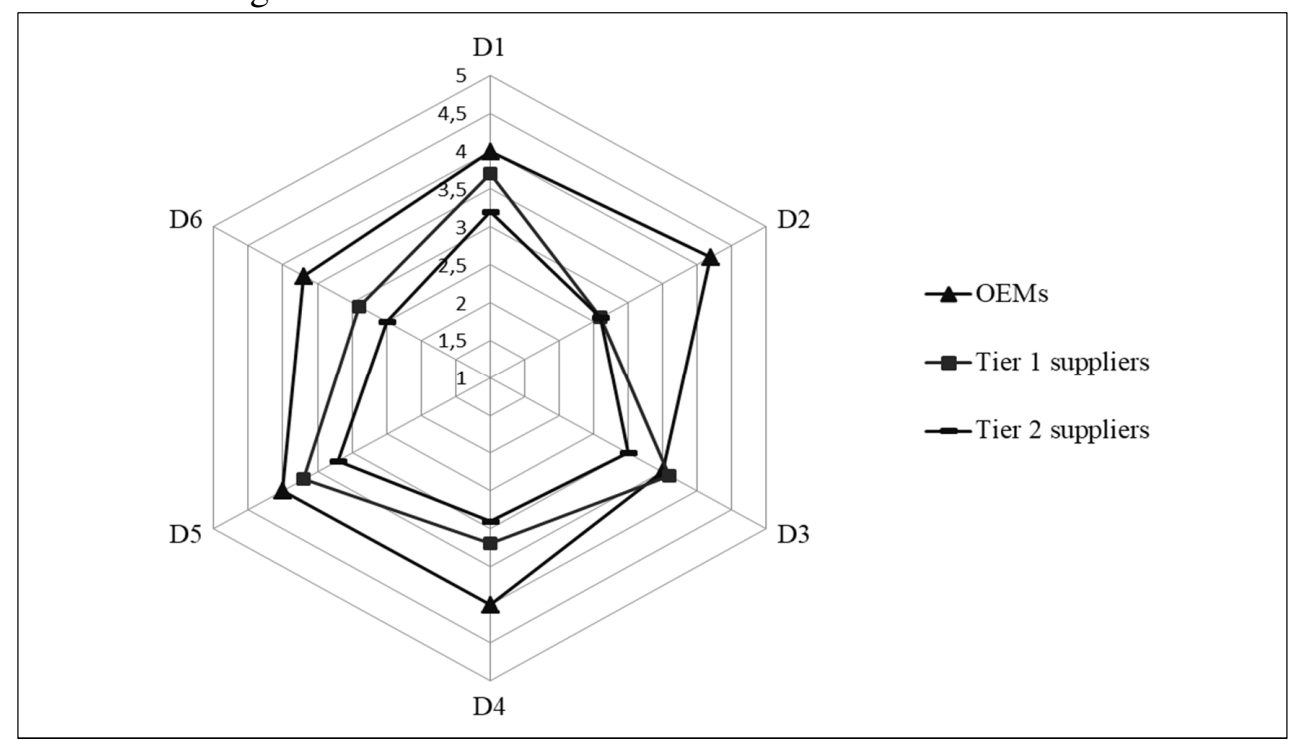

Figure 2 - Average Values of the Industry 4.0 Dimensions

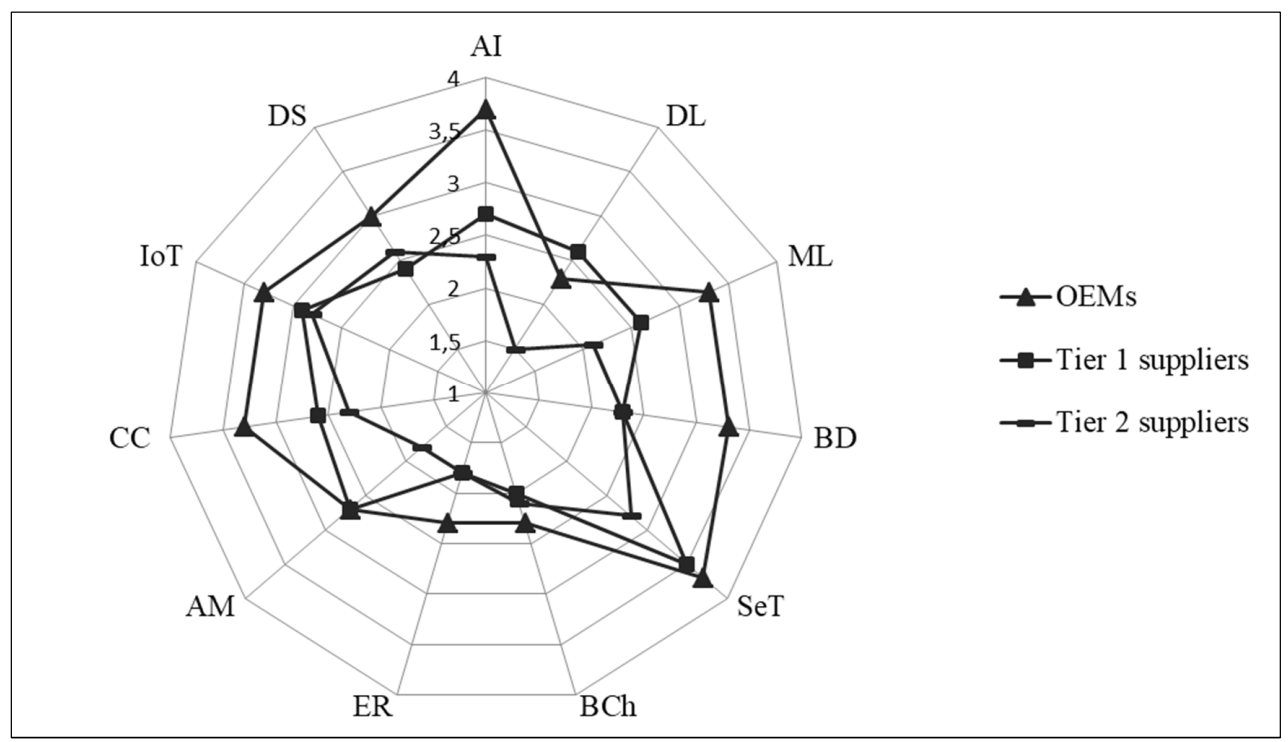

Figure 3 - Average Adoption Level of the Q4.0 Intelligent Technologies

The average adoption of Q4.0 technologies achieves the highest level at OEMs. The statistically, significant differences are only in the application of artificial intelligence and machine learning in comparison to Tier 2 suppliers $(t=2.5280$, 
$\mathrm{p}=0.0162)$. There is no significant difference in Q4.0 adoption between OEMs and Tier 1 suppliers. OEMs have adopted the Q4.0 technologies (Artificial Intelligence, Sensing Technologies, Big data technologies, Cloud Computing, and IoT) mostly at an average level. However, they are early adopters of Deep Learning, Extended Reality, and Blockchain, which have the potential in achieving of the high level of quality. The lowest adoption levels of Q4.0 technologies are in the case of Tier 2 suppliers. Tier 2 suppliers don't use Extended Reality, Blockchain, Additive Manufacturing and Deep Learning or to a very small extent and they are in the early stages of implementation of the other Q4.0 technologies. Tier 1 suppliers rated the usage of Q4.0 technologies slightly higher than Tier 2 suppliers. However, the statistically significant difference between Tier 1 and Tier 2 suppliers $(t=2.8468 ; \mathrm{p}=0.0056)$ is only in the application of deep learning. Sensing technologies were rated by Tier 2 suppliers on the level of the intermediate adopter. Figure 3 shows the average adoption level of Q4.0 technologies of the three groups of respondents.

Resulting from the literature review and studies highlighting the differences in I4.0 readiness and maturity on country levels, the organisation with the highest I4.0 maturity and Q4.0 adoption level and their headquarters location were identified. The best results among Tier 1 suppliers achieve organisations with their headquarters in Germany, USA, and France (totally from 9 countries) and among the Tier 2 suppliers organisations having headquarters in Germany, Australia and Norway (totally from 8 countries). The headquarter organisations have a specific impact on the I4.0 strategy, processes, and technologies used in subsidiary companies operating in Slovakia, but there is also the impact of digital skills of employees as well as organisation culture. One of the key challenges for organisations operating in the automotive industry in Slovakia is the lack of qualified employees. Learning and development form part of the organisation's management strategy and aims to improve group and individual performance by increasing skills and knowledge for I4.0 and the usage of intelligent technologies. The study identified the training and development needs of OEMs, Tier 1, and Tier 2 suppliers and provides input for the systematic learning and development process.

\section{CONCLUSION}

The research contributes to the possibility of identification of learning and development needs to fulfil I4.0 strategy and related Q4.0 intelligent technologies adoption in OEMs, Tier 1 and Tier 2 suppliers operating in Slovakia on the base of the Seven-Step I4.0 and Q4.0 Learning and Development Model. It also contributes to filling the knowledge gap related to I4.0 MM application in the concrete industry sector. The model can be used by any organization operating in the automotive industry for the systematic assessment of I4.0 maturity and related Q4.0 technology adoption and identification of the current state as well as internal and external benchmarking and developing a roadmap to 
achieve improvement. To begin with the systematic approach, it is vital to understand the current maturity and define the path that needs to undertake learning and development towards improvement and higher competitiveness of automotive organisation operating in Slovakia.

The results of the study are limited by the sample size and identification of the target levels and significance of particular dimensions and related elements as well as Q4.0 intelligent technologies which should be achieved from the perspective of organisations and its strategic direction to determine gaps between the current state and future goals and to identify the priorities of learning and development for individual organizations, what will be the subject of further research. Future research will be also focused on the clustering of automotive organizations based on the data obtained from respondents.

\section{ACKNOWLEDGEMENTS}

The study was carried out as a part of the research project VEGA 1/0633/20 "Research of the variability of properties and functions of products made of composite materials produced by additive manufacturing" supported by the Ministry of Education, Science, Research and Sport of the Slovak Republic.

\section{REFERENCES}

Alcácer, V. and Cruz-Machado, V., 2019. Scanning the Industry 4.0: A Literature Review on Technologies for Manufacturing Systems. Engineering Science and Technology, an International Journal [e-journal], 22(3), pp.899-919. doi: 10.1016/j.jestch.2019.01.006.

Asdecker, B. and Felch, V., 2018. Development of an Industry 4.0 maturity model for the delivery process in supply chains. Journal of Modelling in Management [e-journal], 13(4), pp.840-883. doi: 10.1108/JM2-03-2018-0042.

Athanasopoulou, A., Reuver, M., Nikou, S. and Bouwman, H., 2019. What technology enabled services impact business models in the automotive industry? An exploratory study. Futures [e-journal], 109, pp.73-83. doi: 10.1016/j.futures.2019.04.001.

Bakertilly, 2019. Industry 4.0 and the Industrial Internet of Things (IIoT). [online] Available at: <https://bakertilly.com/industry-4.0/> [Accessed 09 January 2020].

Becker, J., Knackstedt, R. and Pöppelbuß, J., 2009. Developing Maturity Models for IT Management: A Procedure Model and its Application for IT Management. Business \& Information Systems Engineering [e-journal], 1(3), pp.213-222. doi: 10.1007/11576-009-0167-9.

Berger, R., 2014. Industry 4.0: The New Industrial Revolution. Munich: Operations Strategy Competence Center. 
Bibby, L. and Dehe, B., 2018. Defining and assessing industry 4.0 maturity levels- case of the defence sector. Production Planning \& Control, 29(12), pp.1030-1043.

Boyes, H., Hallaq, B., Cunningham, J. and Watson, T., 2018. The industrial internet of things (IIoT): An analysis framework. Computers in Industry [ejournal], 101, pp.1-12. doi: 10.1016/j.compind.2018.04.015.

Buchi, G., Cugno, M. and Castagnoli, R., 2020. Smart factory performance and Industry 4.0. Technological Forecasting and Social Change [e-journal], 150, 119790. doi: 10.1016/j.techfore.2019.119790.

Capgemini, 2018. Industry 4.0 Maturity Model - Mirroring today to sprint into the future. [online] Available at: <https://www.capgemini.com/fien/2018/09/industry-4-0-maturity-model-mirroring-today-to-sprint-into-thefuture/> [Accessed 10 May 2019].

Dan, J., 2017. LNS research. [online] Available at: <https://blog.Insresearch.com/quality40> [Accessed 05 May 2019].

European Automobile Manufacturers Association (ACEA), 2018. EU Motor Vehicle Production. [online] Available at: <https://www.acea.be/statistics/article/motor-vehicle-production-in-the-eu> [Accessed 20 Juny 2020].

European Commision, 2019. Integration of Digital Technology: DESI Report. Brussels: European Commision.

Facchini, F., Oleśków-Szłapka, J., Ranieri, L. and Urbinati, A., 2020. A Maturity Model for Logistics 4.0: An Empirical Analysis and a Roadmap for Future Research. Sustainability [e-journal], 12(1), pp.1-18. doi: 10.3390/su12010086.

Felch, V., Asdecker, B. and Sucky, E., 2019. Maturity Models in the Age of Industry 4.0 - Do the Available Models Correspond to the Needs of Business Practice? In: Tung Bui, ed. 52nd Hawaii International Conference on System Sciences. Maui, Hawaii, 08 - 11 January 2019. Honolulu: HICSS. pp.5165-5174. doi: $10.24251 /$ hicss.2019.620.

Geissbauer, R., Vedsø, J. and Schrauf, S., 2016. A Strategist's Guide to Industry 4.0. Srategy + Business, 83(3), pp.10-18.

Grieger, M. and Ludwig, A., 2019. On the move towards customer-centric business models in the automotive industry - a conceptual reference framework of shared automotive service systems. Electronic Markets [e-journal], 29(3), pp.473-500. doi: 10.1007/s12525-018-00327-6.

Hevner, A., March, S. and Park, J.R.S., 2004. Design science in information systems research. MIS Quarterly [e-journal], 28(1), pp.75-105. doi: $10.2307 / 25148625$.

Konrad, K. and Stagl, S., 2018. Competitiveness of the European automotive manufacturing industry. Berlin: Institute for Innovation and Technology. 
Krubasik, S., Dirlea, V., Kidambi, R. and Sachseneder, C., 2017. A.T.Kearney. [online] Available at: <https://www.atkearney.com/industrial-goodsservices/article/?/a/quality-4-0-preventive-holistic-future-proof $>$ [Accessed 28 May 2019].

Lichtblau, K., Stich, V., Bertenrath, R., Blum, M., Bleider, M., Millack, A., Schmitt, K., Schmitz, E. and Schröter, M., 2015. Industrie 4.0 Readiness. Cologne: Aachen University.

Llopis-Albert, C., Rubio, F. and Valero, F., 2021. Impact of digital transformation on the automotive industry. Technological Forecasting and Social Change [e-journal], 162, 120343. doi: 10.1016/j.techfore.2020.120343.

Markulik, Š., Sinay, J. and Pačaiová, H., 2019. Quality Assurance in the Automotive Industry and Industry 4.0. In: D. Cagáňová, M. Balog, L. Knapčíková, J. Sociar and S. Mezarcioz, eds. 2019. Smart Technology Trends in Industrial and Business Management. Switzerland: Springer. pp.217-225. doi: 10.1007/978-3-319-76998-1_15.

Mohelska, H. and Sokolova, M., 2018. Management Approaches for Industry 4.0 - The Organizational Culture Perspective. Technological and Economic Development of Economy [e-journal], 24(6), pp.2225-2240. doi: 10.3846/tede.2018.6397.

Nagyová, A., Pačaiová, H., Gobanová, A. and Turisová, R., 2019. An Empirical Study of Root-Cause Analysis in Automotive Supplier Organisation. Quality Innovation Prosperity [e-journal], 23(2), pp.34-45. doi: 10.12776/qip.v23i2.1243.

Organisation for Economic Cooperation and Development (OECD), 2019. OECD Economic Surveys: Slovac Republic 2019. OECD.

Pereira, A. and Romero, F., 2017. A review of the meanings and the implications of the Industry 4.0 concept. Procedia Manufacturing [e-journal], 13, pp.12061214. doi: 10.1016/j.promfg.2017.09.032.

PricewaterhouseCoopers (PwC), 2016. Industry 4.0 Self Assessment. [online] Available at: <https://i40-self-assessment.pwc.nl/i40/landing/> [Accessed 05 March 2019].

Radziwill, N., 2018. Let's Get Digital: The many ways the fourth industrial revolution is reshaping the way we think about quality. Quality Progress, pp.2429.

Rachinger, M., Rauter, R., Müller, C., Vorraber, W. and Schirgi, E., 2019. Digitalization and its influence on business model innovation. Journal of Manufacturing Technology Management [e-journal], 30(8), pp.1143-1160. doi: 10.1108/JMTM-01-2018-0020.

Rockwell Automation, 2014. The Connected Enterprise Maturity Model. Rockwell Automation. 
Sanders, A., Elangeswaran, C. and Wulfsberg, J.P., 2016. Industry 4.0 implies lean manufacturing: Research activities in industry 4.0 function as enablers for lean manufacturing. Journal of Industrial Engineering and Management [ejournal], 9(3), pp.811-833. doi: 10.3926/jiem.1940.

Schumacher, A., Erol, S. and Sihn, W., 2016. A Maturity Model for Assessing Industry 4.0 Readiness and Maturity of Manufacturing Enterprises. Procedia CIRP [e-journal], 52, pp.161-166. doi: 10.1016/j.procir.2016.07.040.

Slimák, I. and Zgodavová, K., 2011. Focus on Sucess. Quality Innovation Prosperity [e-journal], 15(1), pp.1-4. doi: 10.12776/qip.v15i1.36.

Slovak Investment and trade development agency (SARIO), 2018. Automotive Sector in Slovakia. Bratislava: SARIO.

Tkáć, M., Verner, R. and Tkáč, M., 2019. Perception of trust building mechanisms in EU countries. In: P. Doucek, C. Chroust and V. Oškrdal, eds., IDIMT-2019: Proceedings of the 27th Interdisciplinary Information Management Talks. Kutná Hora, Czech Republic, 04 - 06 September 2019. Linz: TRAUNER Verlag. pp.275-283.

Veile, J., Kiel, D., Muller, J. and Voigt, K., 2019. Lessons learned from Industry 4.0 implementation in the German manufacturing industry. Journal of Manufacturing Technology Management [e-journal], 21p. doi: 10.1108/jmtm-082018-0270.

Weber, C., Königsberger, J., Kassner, L. and Mitschang, B., 2017. M2DDM - A Maturity Model for Data-Driven Manufacturing. Procedia CIRP [e-journal], 63, pp.173-178. doi: 10.1016/j.procir.2017.03.309.

Wellner, P., Manolian, A.H. and Laaper, S., 2018. Distinctive traits of digital frontrunners in manufacturing. Deloitte.Insigts [online] 23 August 2018. Available at: <https://www2.deloitte.com/insights/us/en/focus/industry-40/digital-leaders-in-manufacturing-fourth-industrial-revolution.html $>$ [Accessed 12 December 2018].

World Economic Forum (WEF), 2018. Readiness for the Future of Production. Geneva: WEF.

Zgodavová, K., 2002. Factors of intensive product and service quality improvement. Ekonomický časopis, 50(6), pp.1005-1021.

Zgodavova, K., Hudec, O. and Palfy, P., 2017. Culture of quality: insigth into foreign organisations in Slovakia. Total Quality Management \& Business Excellence [e-journal], 28(9-10), pp.1-22. doi: 10.1080/14783363.2017.1309120. 


\section{ABOUT AUTHORS}

Andrea Sütőová - (A.S.) Technical University of Kosice, Institute of Materials and Quality Engineering, Košice, Slovakia, Assist. Prof., e-mail: andrea.sutoova@tuke.sk, Author's ORCID: 0000-0002-6689-046X.

Lubomír Šooš - (L.Š.) Slovak University of Technology in Bratislava, Institute of Manufacturing Systems, Environmental Technology and Quality Management, Bratislava, Slovakia, Prof., e-mail: lubomir.soos@stuba.sk, Author's ORCID: 0000-0003-3161-5609.

Ferdinand Kóča - (F.K.) Technical University of Kosice, Institute of Materials and Quality Engineering, Košice, Slovakia, PhD. Student, e-mail: ferdinand.koca@student.tuke.sk.

\section{AUTHOR CONTRIBUTIONS}

A.S. - conceptualization, methodology, data curation, original draft preparation; L.Š. - data acquisition, review and editing; F.K. - investigation, visualization.

\section{CONFLICTS OF INTEREST}

The authors declare no conflict of interest. The funders had no role in the design of the study; in the collection, analyses, or interpretation of data; in the writing of the manuscript, or in the decision to publish the results.

(C) 2020 by the authors. Submitted for possible open access publication under the terms and conditions of the Creative Commons Attribution (CC-BY) license (http://creativecommons.org/licenses/by/4.0/). 